\title{
New-onset atrial fibrillation in critically ill patients with coronavirus disease 2019 (COVID-19)
}

\author{
BİŞAR ERGÜN ${ }^{1}$, BEGUM ERGAN², Melih Kaan SÖZMEN, Mehmet Nuri YAKAR $^{1}$, \\ Murat KÜÇÜK ${ }^{1}$, Bilgin CÖMERT ${ }^{1}$, Necati Gokmen ${ }^{4}$, and Erdem YAKA ${ }^{1}$ \\ ${ }^{1}$ Dokuz Eylül University \\ ${ }^{2}$ Affiliation not available \\ ${ }^{3}$ Izmir Katip Celebi University \\ ${ }^{4}$ Dokuz Eylul Universitesi Tip Fakultesi
}

March 20, 2021

\begin{abstract}
Abstract Objectives: To determine the incidence, risk factors, and outcomes of new-onset atrial fibrillation (NOAF) in a cohort of critically ill patients with coronavirus disease 2019 (COVID-19). Methods: We conducted a retrospective study on patients admitted to the intensive care unit (ICU) with a diagnosis of COVID-19. NOAF was defined as atrial fibrillation that was detected after diagnosis of COVID-19 without a prior history. The primary outcome of the study was the effect of NOAF on mortality in critically ill COVID-19 patients. Results: We enrolled 248 eligible patients. NOAF incidence was $14.9 \%$ ( $\mathrm{n}=37$ ), and $78 \%$ of patients $(n=29)$ were men in NOAF positive group. Median age of the NOAF group was 79.0 (interquartile range, $71.5-84.0)$. Hospital mortality was higher in the NOAF group ( $87 \%$ vs $67 \%$, respectively, $\mathrm{p}=0.019)$. However, in multivariate analysis, NOAF was not an independent risk factor for hospital mortality (OR 1.42, 95\% CI 0.40-5.09, p=0.582) Conclusions: The incidence of NOAF was $14.9 \%$ in critically ill COVID-19 patients. Hospital mortality was higher in the NOAF group. However, NOAF was not an independent risk factor for hospital mortality in patients with COVID-19. Keywords: Atrial fibrillation, critical care, intensive care unit, COVID-19, mortality, hospital mortality
\end{abstract}

\section{Introduction}

Coronavirus disease 2019 (COVID-19) is a pneumonia outbreak caused by Severe Acute Respiratory Syndrome Coronavirus 2 (SARS-CoV-2) and began in December 2019. ${ }^{1}$ Although the main involvement is in the respiratory system, there are also many other systemic manifestations including cardiac problems. Acute cardiac injury, which is defined by troponin I elevation has recently been reported with increased hospital mortality in patients with COVID-19. ${ }^{2-4}$

The incidence of cardiac arrhythmia was reported at a rate of $16.7 \%$ in patients with COVID-19 and the incidence increases up to $44.4 \%$ in the intensive care unit (ICU) setting. ${ }^{5}$ Similarly, in another study, cardiac arrhythmia was reported in $18.5 \%$ of 130 patients who had mechanical ventilation requirements. ${ }^{6}$

It was shown that hospitalized patients with COVID-19 with atrial fibrillation (AF) and atrial flutter history had a higher mortality rate than those without AF. ${ }^{7}$ However, the data for the incidence of new-onset AF (NOAF) in patients with COVID-19 are limited. The most common type of new arrhythmia in COVID-19 infection was AF, and AF was mostly detected in the ICU setting. ${ }^{8,9}$ In a study, NOAF incidence was $7.5 \%$ in patients hospitalized for COVID-19. ${ }^{10}$

Although systemic inflammation is an important factor that triggers NOAF development,${ }^{11}$ the pathophysiology of NOAF in COVID-19 has not yet been fully clarified. The proposed mechanisms are hypoxemia, 
increased inflammatory response, and myocardial damage caused by cytokine crisis, increased catecholamines, direct viral endothelial damage, electrolyte and acid-base abnormalities. ${ }^{12,13}$

The ICU mortality in COVID-19 is $35.5 \%,{ }^{14}$ and the rate increases up to $45 \%$ in patients who require invasive mechanical ventilation. ${ }^{15}$ Several other risk factors for mortality were defined such as older age, male sex, higher body mass index (BMI), elevated levels of D-dimer, lactate, and presence of active cancer, coronary artery disease, liver, and kidney dysfunction in patients admitted to ICU. ${ }^{16,17}$ However, it is still not known whether the development of NOAF in critically ill COVID-19 patients affects prognosis. Therefore, this study aimed to determine the incidence of NOAF development in critically ill COVID-19 patients, identify possible risk factors for NOAF development, and evaluate its effect on mortality.

\section{Methods}

\subsection{Study population}

After approvals from the local ethics committee (with date 01.02.2021 and number 2021/04-27) and the Turkish Ministry of Health, the retrospective cohort study was conducted in adult ICUs of our center. All adult patients (age [?] 18 years) diagnosed with COVID-19 infection were included in the study between March 2020 and January 2021. SARS-CoV-2 infection was confirmed by either using reverse transcriptase polymerase chain reaction (RT-PCR) testing on respiratory samples and/or with clinical characteristics, laboratory, and computed tomography findings. The exclusion criteria of the study were having chronic AF diagnosis before COVID-19 diagnosis, presence of cardiac pacemaker/implantable cardioverter-defibrillator, atrial flutter, and NOAF development immediately after cardiopulmonary resuscitation.

\subsection{Definition for NOAF}

The NOAF group consisted of patients who had all of the following criteria: first AF attack after hospitalization for COVID-19, NOAF attack continuing for at least one hour, and need for medical and/or electrical cardioversion. 12-derivation electrocardiography (ECG) record is routinely obtained from all patients at the time of admission to the ICU in our center (number of beds $=30$ ). All beds are monitored in the ICU, and nurse to bed ratio was $1 / 2$. When there was either monitor image/alarm or examination findings that are compatible with AF, an immediate 12-derivation ECG was recorded and the intensivist and/or cardiologist confirmed the definite NOAF diagnosis. The treatment, medical and/or electrical cardioversion, was decided according to the clinical condition of the patient.

\subsection{Other definitions}

The cardiac injury was defined as an increase in high-sensitive (HS) troponin I levels above the 99thpercentile upper reference limit. ${ }^{2}$ Acute kidney injury (AKI) was identified according to the Kidney Disease: Improving Global Outcomes definition. ${ }^{18}$ Ventilator-associated pneumonia (VAP) was defined as pneumonia occurring more than $48 \mathrm{~h}$ after patients have been intubated and received mechanical ventilation. VAP was identified using a combination of positive culture results from respiratory specimen, clinical, laboratory, and radiological findings. ${ }^{19}$ Acute myocardial infarction was defined according to the fourth universal definition of myocardial infarction, ${ }^{20}$ and cardiologist confirmation.

\subsection{Variables}

The demographic data (age, gender, BMI, smoking history, comorbidities), Charlson Comorbidity Index (CCI), Acute Physiology and Chronic Health Evaluation (APACHE) II, and Sequential Organ Failure Assessment (SOFA) Scores, were recorded. Disease characteristics for COVID-19 including the date for symptom onset, RT-PCR results, radiological, and blood tests were collected. Major events during ICU stay (presence of septic shock, presence of cardiac injury, ICU acquired infections including VAP, mechanical ventilation support, AKI, and renal replacement therapy [RRT]) were recorded. The durations from symptom onset of the disease to the development of NOAF were recorded. Lengths of ICU, and hospital stays, and mortality were recorded.

\subsection{Statistical analysis}


The primary outcome of the study was whether the presence of NOAF is a risk factor for mortality in COVID19. Secondary outcomes were the risk factors associated with the development of NOAF. All categorical variables are expressed as numbers and percentages, and continuous variables were expressed as median and interquartile range (IQR). Categorical variables between groups were compared with chi-square or Fisher's exact test, continuous variables were compared with Mann-Whitney $U$-test. The independent effect of NOAF on hospital mortality was assessed with multivariate logistic regression analysis. To build the model, a purposeful selection method was used to select a subset of covariates that were considered clinically important, adjusting for confounders and statistical significance. An adjusted odds ratio (OR) and a 95\% confidence interval (CI) were reported for each independent factor. A two-tailed $P$-value of $<0.05$ was considered statistically significant. Statistical analysis was performed using SPSS (Statistical Package for the Social Sciences Version 24, IBM Corp., Armonk, N.Y., USA)

\section{Results}

\subsection{General characteristics}

A total of 248 of 301 patients who were admitted to ICU with suspicion of COVID-19 infection were included in the study. Of them, $37(14.9 \%)$ had NOAF (Figure 1). NOAF positive group was older than the NOAF negative group (79.0 [71.5-84.0] vs 70.0 [60.0-78.0] years, $\mathrm{p}<0.001$; Table 1$)$.

The median duration from the onset of the COVID-19 infection symptoms to NOAF development was 10.0 (5.0-17.0) days. The median duration from hospitalization to NOAF development was 7.0 (2.0-12.5) days, and the median duration from ICU admission to NOAF development was 3.0 (0.0-10.0) days.

Chronic obstructive pulmonary disease (COPD) (24.3\% vs. $10.9 \%$, respectively; $\mathrm{p}=0.03$ ), and chronic kidney disease $(\mathrm{CKD})(27.0 \%$, vs. $13.3 \%$, respectively; $\mathrm{p}=0.046)$ were more common in the NOAF positive group than the NOAF negative group. CCI median score was higher in the NOAF positive group than the NOAF negative group as well (6.0 [5.0-7.0] vs. 4.0 [2.0-6.0], respectively, $\mathrm{p}=0.003)$. NOAF positive group had higher blood urea nitrogen (BUN) than the NOAF negative group median values (37.1 [28.4-75.0] vs. $30.0[21.0-50.0] \mathrm{mg} / \mathrm{dL}$, respectively, $\mathrm{p}=0.003)$.

\subsection{Cardiopulmonary complications}

It was found that the median B-type natriuretic peptide (BNP) level was higher in the NOAF positive group compared to the NOAF negative group (366 [112-850] vs. 96 [41-277] pg/mL, respectively, $\mathrm{p}=0.001)$. The BNP levels of $114(46.0 \%)$ patients were $>100 \mathrm{pg} / \mathrm{mL}$, which is the upper limit of normal range, and the proportion of NOAF positives was higher than the rate of NOAF negatives $(64.9 \%$, vs. $42.7 \%$, respectively; $\mathrm{p}=0.003)$. The median level for HS troponin I was higher in the NOAF positive group than the NOAF negative group (78.0 [17.9-325.0] vs $27.0[9.7-118.0] \mathrm{ng} / \mathrm{L}$ respectively, $\mathrm{p}=0.02)$.

Cardiac injury was detected in $159(64.1 \%)$ patients. Although the rate for cardiac injury was higher in the NOAF positive group than the NOAF negative group it did not reach a statistical significance $(75.7 \%$, vs. $62.1 \%$, respectively; $\mathrm{p}=0.13)$. Acute myocardial infarction was detected in 10 patients $(4.0 \%)$ after the COVID-19 diagnosis. None of these patients had NOAF. Pulmonary embolism (PE) was detected in 6 patients $(2.4 \%)$ after the COVID-19 diagnosis. It was shown that the incidental PE rate was higher in the NOAF positive group than the NOAF negative group $(8.1 \%$ vs. $1.4 \%$, respectively; $\mathrm{p}=0.045)$. All the PE attacks were diagnosed before the NOAF attack.

\subsection{Major events during ICU stay}

AKI and VAP were more frequent in the NOAF positive group than the NOAF negative group (for AKI $70.3 \%$, vs. $51.7 \%$, respectively; $\mathrm{p}=0.048$ and for VAP $54.1 \%$, vs. $35.5 \%$, respectively; $\mathrm{p}=0.04$ ). The percentage of patients with secondary bacterial infection was significantly higher in the NOAF positive group than the NOAF negative group ( $75.7 \%$ vs. $51.7 \%$, respectively; $\mathrm{p}=0.007)$.

3.4. Length of stays and mortality 
No differences were detected in terms of the median length of ICU stay (for NOAF positive group 9.0 [4.515.0] vs for NOAF negative group 7.0 [4.0-14.0] days, $\mathrm{p}=0.21$ ) and median length of hospital stay (for NOAF positive group 15.0 [9.5-20.5] vs for NOAF negative group: 14.0 [9.0-20.0] days, $\mathrm{p}=0.55$ ). Although ICU mortality of patients was higher in the NOAF positive group compared to the NOAF negative group, no statistically significant difference was detected $(83.8 \%$ vs. $67.3 \%$, respectively, $\mathrm{p}=0.052)$. Hospital mortality was higher in the NOAF positive group than the NOAF negative group $(86.5 \%$, vs. $67.3 \%$, respectively, p $=0.019)$.

In this study, hospital mortality was $70.1 \%(\mathrm{n}=174)$. Statistically significant variables for hospital mortality are reported in Table 2 .

\subsection{Logistic regression analysis for hospital mortality}

Multivariable analysis (Table 3) showed vasopressor requirement (OR 12.20, 95\%CI 5.12-29.05, $p<0.001$ ), AKI (OR 5.53, 95\%CI 1.87-10.92, $\mathrm{p}=0.001$ ), and high CCI (OR 1.36, 95\%CI 1.10-1.66, $p=0.003$ ), as factors independently associated with an increased risk of hospital mortality. However, NOAF was not an independent risk factor for hospital mortality (OR 1.42, 95\% CI 0.40-5.09, $\mathrm{p}=0.582$ ).

\section{Discussion}

This retrospective cohort study has two important results. First, NOAF incidence in critically ill COVID-19 patients is $14.9 \%$. NOAF risk was associated with older age and the presence of comorbidities. Second, hospital mortality increases in critically ill COVID-19 patients with NOAF.

The occurrence of NOAF in critically ill COVID-19 patients has not been well described. Some studies have reported atrial arrhythmia and AF episodes in patients with COVID-19, $, 9,21$ and NOAF has mainly occurred in critically ill patients. ${ }^{8}{ }^{8}$ However, in these studies, data of NOAF are limited. NOAF rate was separately reported in one study and incidence of NOAF was $7.5 \%(\mathrm{n}=12)$ of 160 patients who were hospitalized for COVID-19 infection. ${ }^{10}$ We have found that the incidence of NOAF in critically ill patients is $14.9 \%$. Therefore, we think that our findings give important insights for NOAF development in a fragile group of patients.

Cardiac involvement, such as myocardial injury, myocardial ischemia, myocarditis, cardiogenic shock, acute cor pulmonale, thrombotic complications, and arrhythmia were previously reported in patients with COVID$19 .^{3,22}$ It is considered that myocarditis is caused by inflammatory infiltrates damaging the myocardium and myocardial injury without acute ischemic event. ${ }^{23}$ It has been reported that serious infection, severe tissue inflammation, hypoxia, and electrolyte abnormalities may trigger atrial and ventricular arrhythmia. ${ }^{24}$ However, the etiology of cardiac arrhythmias in COVID-19 has not yet been fully clarified. The most proposed mechanisms are hypoxemia because of acute respiratory distress, increased inflammatory response, and myocardial damage caused by cytokine crisis, increase in catecholamine, direct viral endothelial damage, acidbase, and electrolyte abnormalities. ${ }^{12,13}$ Although the patients who had NOAF were more hypoxemic during admission, no significant difference was detected. More comprehensive studies are required to investigate the effect of hypoxemia on NOAF development in patients with COVID-19.

The incubation period for COVID-19 is median 5-6 days; however, can be up to 14 days. ${ }^{25,26}$ This relatively short period is not sufficient for developing fibrosis-related conditions; therefore, it is expected that this short incubation period does not increase the risk of AF. ${ }^{13}$ Since patients with COVID-19 who developed AF were older and had comorbidities, such as hypertension, ${ }^{10,27}$ it was considered that COVID-19 infection triggers NOAF in the presence of a previously predisposing factor. ${ }^{13}$ Our findings are also consistent with these reports as patients who had NOAF in this study were older and had higher CCI as well. It was observed that NOAF was developed during the first days of acute illness (median day 3.0 [0.0-10.0]) which is similar to previously reported..$^{28,29}$

To date, acute cardiac injury was observed between 12.0 to $29.8 \%$ in patients with COVID-19. ${ }^{2-4,30,31}$ The frequency of cardiac injury was $64.1 \%$ in our study and this rate was higher than previously reported. We believe that the higher rate of cardiac injury was probably due to the population studied. Previous reports 
included a heterogeneous group of patients from both ICU and non-ICU settings, however, this study included only critically ill patients with severe illness.

Our results suggest that patients with COPD are more vulnerable to NOAF development. Previously reported risk factors in ICU patients were advanced age, male sex, accompanying cardiovascular diseases, acute renal failure, acute respiratory failure, shock, sepsis, pulmonary artery catheter use, vasopressor use, need for mechanical ventilation, increased fluid load, and organ failure. ${ }^{32,33}$ A study reported that incidental AF frequency was approximately 4 times higher in patients with severe COPD than in non-COPD patients. ${ }^{34}$ NOAF prevalence was between $4.7-15 \%$ in stable patients with COPD, ${ }^{35}$ and around $20-30 \%$ in severe patients with COPD. ${ }^{36}$ Impaired gas exchange and oxidative stress were considered the possible causes triggering NOAF in COPD. ${ }^{37}$ Respiratory failure and hypoxemia because of COVID-19 may have increased the risk of NOAF in this specific group of patients.

In our study, it was also found that NOAF was mostly detected in patients who developed secondary bacterial infections in ICU follow-ups. AF was reported to be the most common arrhythmia in patients with sepsis, ${ }^{38}$ and was also associated with increased mortality in this group of patients. ${ }^{39}$ The use of vasopressor also contributes to NOAF development in septic shock patients. ${ }^{33}$

It was observed that $\mathrm{PE}$ rate was higher in the NOAF positive group than the NOAF negative group in this cohort. We believe that the coexistence of NOAF and PE deserves specific attention in COVID-19. A meta-analysis reported that the PE prevalence was $16.5 \%$ in COVID-19 infection, which is relatively high. ${ }^{40}$ PE-induced ventricular dysfunction and increased atrial tension may be a factor for triggering $\mathrm{AF}^{41}$

New AF attacks have deleterious effects, such as increasing heart rate, causing irregular rhythm and losses in atrial systole, and neurohormonal activation. For this reason, NOAF development can further complicate critical disease or may limit response to therapy. ${ }^{42}$ Cardiac output may decrease because of loss of atrial systole and tachycardia, and acute heart failure may develop. ${ }^{42,43}$ It was found in some studies that NOAF development correlate with the severity of critical illness. ${ }^{44}$

Although no independent relations were detected in some previous studies between NOAF and hospital mortality ${ }^{45-47}$ some studies found that NOAF was associated with increased hospital mortality regardless of the severity of the critical disease. ${ }^{28,48}$ However, in this study, NOAF was not an independent risk factor for hospital mortality in multivariate analysis.

\section{Limitations and strengths of the study}

This study has several limitations. First, the results are from a single center and could not be generalized. Second, it is impossible to differentiate whether NOAF developed due to COVID-19 related cardiac involvement or due to critical illness itself. Third, we could not analyze long-term consequences of NOAF. However, the study has some strengths. We think that our findings are valuable as NOAF development in critical COVID-19 studied to a lesser extent. Second, the diagnostic accuracy for NOAF was high as the diagnosis was confirmed by an intensivist/cardiologist in all cases.

\section{Conclusion}

Understanding the effects of COVID-19 on the cardiovascular system is essential for providing comprehensive medical care. This is especially important for critically ill patients who have a high risk of dying. Early recognition and treatment of arrhythmias including NOAF may improve the prognosis in severe COVID-19 infection.

\section{Funding and Acknowledgements}

None

\section{Author contributions}

B. ERGUN contributed to data collection and analysis, manuscript writing and revision. B. ERGAN and EY contributed to study design, manuscript writing. BC and ANG contributed to literature review, manuscript 
writing. MK and MNY contributed to data collection and analysis. MKS contributed to data analysis and literature review. All authors approved the final version of the article for submission.

\section{References}

1. Zhu N, Zhang D, Wang W, et al. A Novel Coronavirus from Patients with Pneumonia in China, 2019. $N$ Engl J Med . 2020;382(8):727-733. doi:10.1056/nejmoa2001017

2. Shi S, Qin M, Shen B, et al. Association of Cardiac Injury with Mortality in Hospitalized Patients with COVID-19 in Wuhan, China.JAMA Cardiol . 2020;5(7):802-810. doi:10.1001/jamacardio.2020.0950

3. Guo T, Fan Y, Chen M, et al. Cardiovascular Implications of Fatal Outcomes of Patients with Coronavirus Disease 2019 (COVID-19).JAMA Cardiol . 2020;5(7):811-818. doi:10.1001/jamacardio.2020.1017

4. Maeda T, Obata R, Rizk D, Kuno T. Cardiac Injury and Outcomes of Patients with COVID-19 in New York City. Heart Lung Circ . 2020;(January). doi:10.1016/j.hlc.2020.10.025

5. Wang D, Hu B, Hu C, et al. Clinical Characteristics of 138 Hospitalized Patients with 2019 Novel Coronavirus-Infected Pneumonia in Wuhan, China. JAMA - J Am Med Assoc . 2020;323(11):1061-1069. doi:10.1001/jama.2020.1585

6. Goyal P, Choi JJ, Pinheiro LC, et al. Clinical Characteristics of Covid-19 in New York City. $N$ Engl $J$ Med . 2020;382(24):2372-2374. doi:10.1056/nejmc2010419

7. Peltzer B, Manocha KK, Ying X, et al. Outcomes and mortality associated with atrial arrhythmias among patients hospitalized with COVID-19. J Cardiovasc Electrophysiol . 2020;31(12):3077-3085. doi:10.1111/jce. 14770

8. Colon CM, Barrios JG, Chiles JW, et al. Atrial Arrhythmias in COVID-19 Patients. JACC Clin Electrophysiol . 2020;6(9):1189-1190. doi:10.1016/j.jacep.2020.05.015

9. Bhatla A, Mayer MM, Adusumalli S, et al. COVID-19 and cardiac arrhythmias. Heart Rhythm . 2020;17(9):1439-1444. doi:10.1016/j.hrthm.2020.06.016

10. Pardo Sanz A, Salido Tahoces L, Ortega Pérez R, González Ferrer E, Sanchez Recalde Á, Zamorano Gómez JL. New-onset atrial fibrillation during COVID-19 infection predicts poor prognosis. Cardiol $J$. 2020:34-40. doi:10.5603/cj.a2020.0145

11. Meierhenrich R, Steinhilber E, Eggermann C, et al. Incidence and prognostic impact of new-onset atrial fibrillation in patients with septic shock: A prospective observational study. Crit Care . 2010;14(3):R108. doi:10.1186/cc9057

12. Kochi AN, Tagliari AP, Forleo GB, Fassini GM, Tondo C. Cardiac and arrhythmic complications in patients with COVID-19. J Cardiovasc Electrophysiol . 2020;31(5):1003-1008. doi:10.1111/jce.14479

13. Gawałko M, Kapłon-Cieślicka A, Hohl M, Dobrev D, Linz D. COVID-19 associated atrial fibrillation: Incidence, putative mechanisms and potential clinical implications. Int J Cardiol Heart Vasc . 2020;30:100631. doi:10.1016/j.ijcha.2020.100631

14. Armstrong RA, Kane AD, Kursumovic E, Oglesby FC, Cook TM. Mortality in patients admitted to intensive care with COVID-19: an updated systematic review and meta-analysis of observational studies.Anaesthesia . 2021;(May 2020):1-12. doi:10.1111/anae.15425

15. Lim ZJ, Subramaniam A, Reddy MP, et al. Case Fatality Rates for Patients with COVID-19 Requiring Invasive Mechanical Ventilation. Am J Respir Crit Care Med . 2021;203(1):54-66. doi:10.1164/rccm.202006$2405 \mathrm{OC}$

16. Wendel Garcia PD, Fumeaux T, Guerci P, et al. Prognostic factors associated with mortality risk and disease progression in 639 critically ill patients with COVID-19 in Europe: Initial report 
of the international RISC-19-ICU prospective observational cohort.EClinicalMedicine . 2020;25:100449. doi:10.1016/j.eclinm.2020.100449

17. Gupta S, Hayek SS, Wang W, et al. Factors Associated with Death in Critically Ill Patients with Coronavirus Disease 2019 in the US.JAMA Intern Med . 2020;02115:1-12. doi:10.1001/jamainternmed.2020.3596

18. Kellum JA, Lameire N, Aspelin P, et al. Kidney disease: Improving global outcomes (KDIGO) acute kidney injury work group. KDIGO clinical practice guideline for acute kidney injury. Kidney Int Suppl . 2012;2(1):1-138. doi:10.1038/kisup.2012.1

19. Spalding MC, Cripps MW, Minshall CT. Ventilator-Associated Pneumonia: New Definitions. Crit Care Clin . 2017;33(2):277-292. doi:10.1016/j.ccc.2016.12.009

20. Thygesen K, Alpert JS, Jaffe AS, et al. Fourth Universal Definition of Myocardial Infarction (2018). $J$ Am Coll Cardiol . 2018;72(18):2231-2264. doi:10.1016/j.jacc.2018.08.1038

21. Iacopino S, Placentino F, Colella J, et al. New-Onset Cardiac Arrhythmias During COVID-19 Hospitalization. Circ Arrhythm Electrophysiol . 2020;13(11):1388-1391. doi:10.1161/CIRCEP.120.009040

22. Gupta A, Madhavan M V., Sehgal K, et al. Extrapulmonary manifestations of COVID-19. Nat Med . 2020;26(7):1017-1032. doi:10.1038/s41591-020-0968-3

23. Esfandiarei M, McManus BM. Molecular biology and pathogenesis of viral myocarditis. Annu Rev Pathol Mech Dis . 2008;3:127-155. doi:10.1146/annurev.pathmechdis.3.121806.151534

24. Antzelevitch C, Burashnikov A. Overview of Basic Mechanisms of Cardiac Arrhythmia. Card Electrophysiol Clin . 2011;3(1):23-45. doi:10.1016/j.ccep.2010.10.012

25. Yu P, Zhu J, Zhang Z, Han Y. A familial cluster of infection associated with the 2019 novel coronavirus indicating possible person-to-person transmission during the incubation period. $J$ Infect Dis . 2020;221(11):1757-1761. doi:10.1093/infdis/jiaa077

26. Lauer SA, Grantz KH, Bi Q, et al. The incubation period of coronavirus disease 2019 (CoVID-19) from publicly reported confirmed cases: Estimation and application. Ann Intern Med . 2020;172(9):577-582. doi:10.7326/M20-0504

27. Sala S, Peretto G, De Luca G, et al. Low prevalence of arrhythmias in clinically stable COVID-19 patients. PACE - Pacing Clin Electrophysiol . 2020;43(8):891-893. doi:10.1111/pace.13987

28. Arrigo M, Ishihara S, Feliot E, et al. New-onset atrial fibrillation in critically ill patients and its association with mortality: A report from the FROG-ICU study. Int $J$ Cardiol . 2018;266:95-99. doi:10.1016/j.ijcard.2018.03.051

29. Guenancia C, Binquet C, Laurent G, et al. Incidence and predictors of new-onset atrial fibrillation in septic shock patients in a medical ICU: Data from 7-day Holter ECG monitoring. PLoS One . 2015;10(5):e0127168. doi:10.1371/journal.pone.0127168

30. Huang C, Wang Y, Li X, et al. Clinical features of patients infected with 2019 novel coronavirus in Wuhan, China. Lancet . 2020;395(10223):497-506. doi:10.1016/S0140-6736(20)30183-5

31. Kuno T, Takahashi M, Obata R, Maeda T. Cardiovascular comorbidities, cardiac injury, and prognosis of COVID-19 in New York City. Am Heart J . 2020;226:24-25. doi:10.1016/j.ahj.2020.05.005

32. Wu Z, Fang J, Wang Y, Chen F. Prevalence, outcomes, and risk factors of new-onset atrial fibrillation in critically ill patients a systematic review. Int Heart $J$. 2020;61(3):476-485. doi:10.1536/ihj.19-511

33. Bedford JP, Harford M, Petrinic T, Young JD, Watkinson PJ. Risk factors for new-onset atrial fibrillation on the general adult ICU: A systematic review. J Crit Care . 2019;53:169-175. doi:10.1016/j.jcrc.2019.06.015 
34. Konecny T, Park JY, Somers KR, et al. Relation of chronic obstructive pulmonary disease to atrial and ventricular arrhythmias. In:American Journal of Cardiology . Vol 114. ; 2014:272-277. doi:10.1016/j.amjcard.2014.04.030

35. Buch P, Friberg J, Scharling H, Lange P, Prescott E. Reduced lung function and risk of atrial fibrillation in the Copenhagen City Heart Study. Eur Respir J . 2003;21(6):1012-1016. doi:10.1183/09031936.03.00051502

36. Martinez $\mathrm{CH}$, Han MLK. Contribution of the environment and comorbidities to chronic obstructive pulmonary disease phenotypes. Med Clin North Am . 2012;96(4):713-727. doi:10.1016/j.mcna.2012.02.007

37. Terzano C, Romani S, Conti V, Paone G, Oriolo F, Vitarelli A. Atrial fibrillation in the acute, hypercapnic exacerbations of COPD. Eur Rev Med Pharmacol Sci . 2014;18(19):2908-2917.

38. Shahreyar M, Fahhoum R, Akinseye O, Bhandari S, Dang G, Khouzam RN. Severe sepsis and cardiac arrhythmias. Ann Transl Med . 2018;6(1):6-6. doi:10.21037/atm.2017.12.26

39. Christian SA, Schorr C, Ferchau L, Jarbrink ME, Parrillo JE, Gerber DR. Clinical characteristics and outcomes of septic patients with new-onset atrial fibrillation. J Crit Care . 2008;23(4):532-536. doi:10.1016/j.jcrc.2007.09.005

40. Suh YJ, Hong H, Ohana M, et al. Pulmonary Embolism and Deep Vein Thrombosis in COVID-19: A Systematic Review and Meta-Analysis.Radiology . 2021;298(2):E70-E80. doi:10.1148/radiol.2020203557

41. Hald EM, Enga KF, Løchen ML, et al. Venous thromboembolism increases the risk of atrial fibrillation: the Tromso study. J Am Heart Assoc . 2014;3(1):1-7. doi:10.1161/JAHA.113.000483

42. Liu WC, Lin WY, Lin CS, et al. Prognostic impact of restored sinus rhythm in patients with sepsis and new-onset atrial fibrillation. Crit Care . 2016;20(1):373. doi:10.1186/s13054-016-1548-2

43. Wang TJ, Larson MG, Levy D, et al. Temporal relations of atrial fibrillation and congestive heart failure and their joint influence on mortality: The Framingham heart study. Circulation . 2003;107(23):2920-2925. doi:10.1161/01.CIR.0000072767.89944.6E

44. Seguin P, Signouret T, Laviolle B, Branger B, Mallédant Y. Incidence and risk factors of atrial fibrillation in a surgical intensive care unit. Crit Care Med . 2004:722-726. doi:10.1097/01.CCM.0000114579.56430.E0

45. Gupta S, Tiruvoipati R, Green C. Atrial fibrillation and mortality in critically ill patients: A retrospective study. Am J Crit Care . 2015;24(4):336-341. doi:10.4037/ajcc2015319

46. Annane D, Sébille V, Duboc D, et al. Incidence and prognosis of sustained arrhythmias in critically III patients. Am J Respir Crit Care Med . 2008;178(1):20-25. doi:10.1164/rccm.200701-031OC

47. Carrera P, Thongprayoon C, Cheungpasitporn W, Iyer VN, Moua T. Epidemiology and outcome of new-onset atrial fibrillation in the medical intensive care unit. J Crit Care . 2016;36:102-106. doi:10.1016/j.jcrc.2016.06.032

48. Shaver CM, Chen W, Janz DR, et al. Atrial fibrillation is an independent predictor of mortality in critically ill patients. Crit Care Med . 2015;43(10):2104-2111. doi:10.1097/CCM.0000000000001166

Figure 1. Flowchart of the study population. 


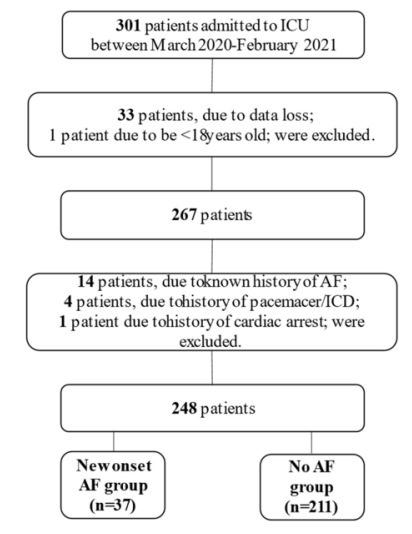

Abbreviations: AF, atrial fibrillation; ICD, implantable cardioverter defibrillator; ICU, intensive care unit.

Table 1. Demographic and clinical characteristics in patients with and without new-onset atrial fibrillation (univariate analysis).

\begin{tabular}{|c|c|c|c|c|}
\hline Characteristics & All Cases & New-onset AF & No AF & $\mathrm{P}$ value \\
\hline & $(\mathrm{N}: 248)$ & (n: 37) & $(\mathrm{n}: 211)$ & \\
\hline Age, years & $71.0(61.0-80.0)$ & $79.0(71.5-84.0)$ & $70.0(60.0-78.0)$ & $<0.001$ \\
\hline Gender & Gender & Gender & Gender & Gender \\
\hline Female & $72(29.0)$ & $8(21.6)$ & $64(30.3)$ & 0.33 \\
\hline Male & $176(71.0)$ & $29(78.4)$ & $147(69.7)$ & \\
\hline $\begin{array}{l}\text { Smoking } \\
\text { history }\end{array}$ & $54(21.8)$ & $11(29.7)$ & $43(20.4)$ & 0.20 \\
\hline $\begin{array}{l}\text { Body mass } \\
\text { index, } \mathrm{kg} / \mathrm{m}^{2}\end{array}$ & $26.0(22.5-29.2)$ & $24.6(20.6-27.7)$ & $26.1(22.5-29.3)$ & 0.07 \\
\hline $\begin{array}{l}\text { RT-PCR } \\
\text { positivity }\end{array}$ & $226(91.1)$ & $36(97.3)$ & $190(90.0)$ & 0.21 \\
\hline Comorbidities & Comorbidities & Comorbidities & Comorbidities & Comorbidities \\
\hline Hypertension & $175(70.6)$ & $31(83.8)$ & $144(68.2)$ & 0.07 \\
\hline Diabetes mellitus & $91(36.7)$ & $14(37.8)$ & $77(36.5)$ & 0.85 \\
\hline $\begin{array}{l}\text { Coronary artery } \\
\text { disease }\end{array}$ & $65(26.2)$ & $11(29.7)$ & $54(25.6)$ & 0.68 \\
\hline $\begin{array}{l}\text { Congestive heart } \\
\text { failure }\end{array}$ & $39(15.7)$ & $9(24.3)$ & $30(14.2)$ & 0.14 \\
\hline $\begin{array}{l}\text { Valvular heart } \\
\text { disease }^{1}\end{array}$ & $7(2.8)$ & $2(5.4)$ & $5(2.4)$ & 0.28 \\
\hline$\underset{2}{\text { Neurological disease }}$ & $47(19.0)$ & $11(29.7)$ & $36(17.1)$ & 0.10 \\
\hline $\begin{array}{l}\text { Chronic kidney } \\
\text { disease }\end{array}$ & $38(15.3)$ & $10(27.0)$ & $28(13.3)$ & 0.046 \\
\hline$C O P D$ & $32(12.9)$ & $9(24.3)$ & $23(10.9)$ & 0.03 \\
\hline Malignancy $^{3}$ & $30(12.1)$ & $4(10.8)$ & $26(12.3)$ & 1.00 \\
\hline Hyperlipidemia & $15(6.0)$ & $2(5.4)$ & $13(6.2)$ & 1.00 \\
\hline $\begin{array}{l}\text { Chronic liver } \\
\text { disease }\end{array}$ & $2(0.8)$ & $0(0.0)$ & $2(0.9)$ & 1.00 \\
\hline
\end{tabular}




\begin{tabular}{|c|c|c|c|c|}
\hline Characteristics & All Cases & New-onset AF & No AF & $\mathrm{P}$ value \\
\hline APACHE II & $22.0(12.0-28.0)$ & $24.0(16.5-27.0)$ & $20.0(11.0-28.0)$ & 0.15 \\
\hline SOFA $^{4}$ & $5.0(3.0-7.0)$ & $6.0(4.0-7.5)$ & $5.0(3.0-7.0)$ & 0.14 \\
\hline CCI & $5.0(2.0-7.0)$ & $6.0(5.0-7.0)$ & $4.0(2.0-6.0)$ & 0.003 \\
\hline $\begin{array}{l}\text { Laboratory } \\
\text { data }^{5}\end{array}$ & $\begin{array}{l}\text { Laboratory } \\
\text { data }^{5}\end{array}$ & $\begin{array}{l}\text { Laboratory } \\
\text { data }^{5}\end{array}$ & $\begin{array}{l}\text { Laboratory } \\
\text { data }^{5}\end{array}$ & $\begin{array}{l}\text { Laboratory } \\
\text { data }^{5}\end{array}$ \\
\hline$B U N, m g / d L$ & $31.0(23.0-51.0)$ & $37.1(28.4-75.0)$ & $30.0(21.0-50.0)$ & 0.003 \\
\hline Creatinine, $m g / d L$ & $1.03(0.79-1.64)$ & $1.03(0.87-2.17)$ & $1.03(0.79-1.56)$ & 0.09 \\
\hline $\begin{array}{l}\text { Total } \\
\text { bilirubin.mg/dL }\end{array}$ & $0.83(0.62-1.14)$ & $0.96(0.63-1.22)$ & $0.81(0.62-1.12)$ & 0.27 \\
\hline$A L T, U / L$ & $37.0(24.0-63.7)$ & $34.0(24.0-58.5)$ & $37.0(24.0-65.0)$ & 0.60 \\
\hline$A S T, U / L$ & $52.0(38.0-90.7)$ & $57.0(38.5-10.5)$ & $52.0(38.0-91.0)$ & 0.69 \\
\hline$L D H, U / L$ & $554(415-705)$ & $521(357-654)$ & $555(422-726)$ & 0.18 \\
\hline Ferritin $n g / m L$ & $622(338-1130)$ & $627(298-1562)$ & $617(340-1121)$ & 0.79 \\
\hline$H S$-troponin $I, n g / L$ & $29.0(11.0-126.2)$ & $78.0(17.9-325.0)$ & $27.0(9.7-118.0)$ & 0.02 \\
\hline$\Delta-\delta \imath \mu \epsilon \rho, \mu \gamma / \mu \Lambda$ & $1.60(1.00-3.87)$ & $1.90(1.20-10.75)$ & $1.60(0.90-3.60)$ & 0.10 \\
\hline $\begin{array}{l}B N P \text { (plasma), } \\
\mathrm{pg} / \mathrm{mL}^{*}\end{array}$ & $118(46-324)$ & $366(112-850)$ & $96(41-277)$ & 0.001 \\
\hline$C R P, m g / L$ & $155.0(84.7-228.2)$ & $158.0(104.0-219.5)$ & $154.0(83.0-228.7)$ & 0.83 \\
\hline $\begin{array}{l}\text { Procalcitonin, } \\
\mathrm{ng} / \mathrm{mL}\end{array}$ & $0.33(0.13-1.14)$ & $0.41(0.18-1.80)$ & $0.32(0.11-1.13)$ & 0.15 \\
\hline$\Omega B^{\prime \prime}, \xi 10^{3} / \mu \Lambda$ & $11.1(7.9-15.1)$ & $11.0(7.5-16.7)$ & $11.2(7.9-15.0)$ & 0.96 \\
\hline 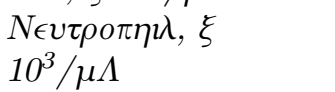 & $9.6(6.8-13.9)$ & $9.5(6.4-14.1)$ & $9.6(6.8-14.0)$ & 0.87 \\
\hline $\begin{array}{l}\Lambda \psi \mu \pi \eta \circ \varsigma \psi \varsigma \tau \epsilon, \xi \\
10^{3} / \mu \Lambda\end{array}$ & $0.5(0.3-0.9)$ & $0.5(0.4-0.9)$ & $0.5(0,3-0,9)$ & 0.83 \\
\hline $\begin{array}{l}\text { Lymphocyte } \\
\text { percentages, \% }\end{array}$ & $5.7(3.2-9.4)$ & $5.4(3.1-8.0)$ & $5.8(3.3-9.8)$ & 0.45 \\
\hline Hemoglobin, $g / d L$ & $12.5(10.8-13.8)$ & $12.3(10.2-13.3)$ & $12.5(11.0-13.9)$ & 0.18 \\
\hline$\Pi \lambda a \tau \in \lambda \in \tau, \xi 10^{3} / \mu \Lambda$ & $258(172-337)$ & $226(167-317)$ & $260(173-343)$ & 0.21 \\
\hline$B N P>100 \mathrm{pg} / \mathrm{mL}^{6}$ & $114(46.0)$ & $24(64.9)$ & $90(42.7)$ & 0.003 \\
\hline $\begin{array}{l}H S \text {-Troponin } I>42.9 \\
\mathrm{ng} / \mathrm{L}^{7}\end{array}$ & $107(43.1)$ & $21(56.8)$ & $86(40.8)$ & 0.07 \\
\hline $\begin{array}{l}\text { Arterial blood } \\
\text { gas analysis }\end{array}$ & $\begin{array}{l}\text { Arterial blood } \\
\text { gas analysis }\end{array}$ & $\begin{array}{l}\text { Arterial blood } \\
\text { gas analysis }\end{array}$ & $\begin{array}{l}\text { Arterial blood } \\
\text { gas analysis }\end{array}$ & $\begin{array}{l}\text { Arterial blood } \\
\text { gas analysis }\end{array}$ \\
\hline pH & $7.41(7.32-7.47)$ & $7.38(7.27-7.46)$ & $7.42(7.33-7.47)$ & 0.26 \\
\hline $\mathrm{PaO}_{2}, \mathrm{mmHg}$ & $63.0(53.0-76.0)$ & $58.2(46.0-69.0)$ & $64.0(54.0-78.0)$ & 0.003 \\
\hline $\mathrm{PaCO}_{2}, \mathrm{mmHg}$ & $34.0(30.0-42.0)$ & $33.0(27.5-44.5)$ & $35.0(30.0-41.6)$ & 0.46 \\
\hline $\mathrm{HCO}_{3}, \mathrm{mmol} / \mathrm{L}$ & $22.2(19.6-25.0)$ & $21.0(16.9-24.5)$ & $22.8(20.0-25.0)$ & 0.03 \\
\hline Lactate, $\mathrm{mmol} / \mathrm{L}$ & $2.00(1.40-3.00)$ & $2.10(1.50-3,10)$ & $2.00(1.40-3.00)$ & 0.49 \\
\hline $\mathrm{SO}_{2}, \%$ & $91.0(86.0-94.0)$ & $86.0(80.5-92.5)$ & $91.6(88.0-94.0)$ & 0.002 \\
\hline $\mathrm{PaO}_{2} / \mathrm{FiO}_{2}$ & $113.0(95.2-142.5)$ & $106.0(91.5-122.5)$ & $113.0(96.0-146.0)$ & 0.14 \\
\hline $\begin{array}{l}\mathrm{PaO}_{2} / \mathrm{FiO}_{2}<150, \\
n(\%)\end{array}$ & $193(77.8)$ & $32(86.5)$ & $161(76.3)$ & 0.20 \\
\hline $\begin{array}{l}\text { Events/therapies } \\
\text { during ICU } \\
\text { stay }\end{array}$ & $\begin{array}{l}\text { Events/therapies } \\
\text { during ICU } \\
\text { stay }\end{array}$ & $\begin{array}{l}\text { Events/therapies } \\
\text { during ICU } \\
\text { stay }\end{array}$ & $\begin{array}{l}\text { Events/therapies } \\
\text { during ICU } \\
\text { stay }\end{array}$ & $\begin{array}{l}\text { Events/therapies } \\
\text { during ICU } \\
\text { stay }\end{array}$ \\
\hline$I M V$ & $198(79.8)$ & $33(89.2)$ & $165(78.2)$ & 0.18 \\
\hline $\begin{array}{l}\text { Successfully } \\
\text { weaning }\end{array}$ & $19(7.7)$ & $2(5.4)$ & $17(8.1)$ & 0.53 \\
\hline
\end{tabular}




\begin{tabular}{|c|c|c|c|c|}
\hline Characteristics & All Cases & New-onset AF & No AF & $\mathrm{P}$ value \\
\hline $\begin{array}{l}\text { Vasopressor } \\
\text { requirement }\end{array}$ & $166(66.9)$ & $29(78.4)$ & $137(64.9)$ & 0.13 \\
\hline$V A P$ & $95(38.3)$ & $20(54.1)$ & $75(35.5)$ & 0.04 \\
\hline $\begin{array}{l}\text { Secondary bacterial } \\
\text { infections }\end{array}$ & $137(55.2)$ & $28(75.7)$ & $109(51.7)$ & 0.007 \\
\hline Acute kidney injury & $135(54.4)$ & $26(70.3)$ & $109(51.7)$ & 0.048 \\
\hline $\begin{array}{l}\text { Renal replacement } \\
\text { therapy }\end{array}$ & $66(26.6)$ & $14(37.8)$ & $52(24.6)$ & 0.10 \\
\hline $\begin{array}{l}\text { Acute myocardial } \\
\text { infarction }\end{array}$ & $10(4.0)$ & $0(0.0)$ & $10(4.7)$ & 0.36 \\
\hline Cardiac injury & $159(64.1)$ & $28(75.7)$ & $131(62.1)$ & 0.13 \\
\hline $\begin{array}{l}\text { Acute pulmonary } \\
\text { embolism }\end{array}$ & $6(2.4)$ & $3(8.1)$ & $3(1.4)$ & 0.045 \\
\hline$C P R$ & $9(3.6)$ & $1(2.7)^{* *}$ & $8(3.8)$ & 1.00 \\
\hline Treatment for & Treatment for & Treatment for & Treatment for & Treatment for \\
\hline COVID-19 & COVID-19 & COVID-19 & COVID-19 & COVID-19 \\
\hline Favipravir & $235(94.8)$ & $36(97.3)$ & $199(94.3)$ & 0.69 \\
\hline$L M W H$ & $235(94.8)$ & $35(94.6)$ & $200(94.8)$ & 1.00 \\
\hline$A S A$ & $190(76.6)$ & $27(73.0)$ & $163(77.3)$ & 0.50 \\
\hline Dipyridamole & $147(59.3)$ & $22(59.5)$ & $125(59.2)$ & 1.00 \\
\hline Corticosteroids & $190(76.6)$ & $28(75.7)$ & $162(76.8)$ & 0.83 \\
\hline Pulse corticosteroid & $101(40.7)$ & $17(45.9)$ & $84(39.8)$ & 0.58 \\
\hline Hydroxychloroquine & $56(22.6)$ & $6(16.2)$ & $50(23.7)$ & 0.39 \\
\hline Azithromycin & $9(3.6)$ & $0(0.0)$ & $9(4.3)$ & 0.36 \\
\hline $\begin{array}{l}\text { Length of ICU } \\
\text { stay, days }\end{array}$ & $7.0(4.0-14.0)$ & $9.0(4.5-15.0)$ & $7.0(4.0-14.0)$ & 0.21 \\
\hline $\begin{array}{l}\text { Length of } \\
\text { hospital stay, } \\
\text { days }\end{array}$ & $14.0(9.0-20.0)$ & $15.0(9.5-20.5)$ & $14.0(9.0-20.0)$ & 0.55 \\
\hline ICU mortality & $173(69.8)$ & $31(83.8)$ & $142(67.3)$ & 0.052 \\
\hline $\begin{array}{l}\text { Hospital } \\
\text { mortality }\end{array}$ & $174(70.2)$ & $32(86.5)$ & $142(67.3)$ & 0.019 \\
\hline
\end{tabular}

Note: All values are expressed as numbers (percentages) or median (interquartile range).

Abbreviations: AF, atrial fibrillation; APACHE II, Acute Physiology and Chronic Health Evaluation II; ALT, alanine transaminase; AST, aspartate transaminase; ASA, acetylsalicylic acid; BUN, blood urea nitrogen; BNP, brain natriuretic peptide; CCI, Charlson Comorbidity Index; COPD, chronic obstructive pulmonary disease; CPR, cardiopulmonary resuscitation; CRP, C-reactive protein; $\mathrm{FiO}_{2}$, fraction of Inspired oxygen; HS Troponin I, high-sensitive troponin I; ICU, intensive care unit IMV, invasive mechanical ventilation; LDH, lactate dehydrogenase; LMWH, low molecular weight heparin; NIV, noninvasive ventilation; $\mathrm{PaO}_{2}$, partial pressure of arterial oxygen; $\mathrm{PaCO}_{2}$, partial pressure of arterial carbon dioxide; RT-PCR, reverse transcription-polymerase chain reaction; $\mathrm{SO}_{2}$, arterial oxygen saturation; SOFA Score, The Sequential Organ Failure Assessment Score; VAP, ventilator associated pneumonia; WBC, white blood cell count.

1. Any valvular disease.

2. History of cerebrovascular disease or dementia.

3. Includes hematological and solid organ malignancies.

4. Calculated on the day of ICU admission. 
5. Tested on the day of ICU admission.

6. Laboratory upper limit of BNP (100 pg/mL).

7. Laboratory upper limit of HS-Troponin (42.9 ng/L).

8. Use of any dose of vasopressor.

*. $\mathrm{N}=215$.

** Detected before CPR.

Table 2. Statistically significant variables for hospital mortality (univariate analysis).

\begin{tabular}{|c|c|c|c|c|}
\hline Characteristics & All Cases & Dead group & Alive group & $\mathrm{P}$ value \\
\hline & (N: 248) & $(\mathrm{n}: 174)$ & $(\mathrm{n}: 74)$ & \\
\hline Age, years & $71.0(61.0-80.0)$ & $75.0(66.0-81.2)$ & $61.0(52.0-70.2)$ & $<0.001$ \\
\hline $\begin{array}{l}\text { Body mass } \\
\text { index, } \mathrm{kg} / \mathrm{m}^{2}\end{array}$ & $26.0(22.5-29.2)$ & $25.8(22.0-28.0)$ & $27.0(23.5-30.5)$ & 0.027 \\
\hline Comorbidities & Comorbidities & Comorbidities & Comorbidities & Comorbidities \\
\hline Neurological disease & $47(19.0)$ & $45(25.9)$ & $2(2.7)$ & $<0.001$ \\
\hline $\begin{array}{l}\text { Chronic kidney } \\
\text { disease }\end{array}$ & $38(15.3)$ & $33(19.0)$ & $5(6.8)$ & 0.020 \\
\hline Malignancy & $30(12.1)$ & $27(15.5)$ & $3(4.1)$ & 0.010 \\
\hline APACHE II & $22.0(12.0-28.0)$ & $24.0(15.0-29.2)$ & $12.0(9.0-22.0)$ & $<0.001$ \\
\hline SOFA & $5.0(3.0-7.0)$ & $6.0(4.0-8.0)$ & $3.0(2.0-4.0)$ & $<0.001$ \\
\hline CCI & $5.0(2.0-7.0)$ & $5.5(4.0-7.0)$ & $2.0(1.0-4.0)$ & $<0.001$ \\
\hline Laboratory & Laboratory & Laboratory & Laboratory & Laboratory \\
\hline data & data & data & data & data \\
\hline$B U N, m g / d L$ & $31.0(23.0-51.0)$ & $35.0(26.0-56.2)$ & $24.5(18.0-31.9)$ & $<0.001$ \\
\hline Creatinine, $\mathrm{mg} / \mathrm{dL}$ & $1.03(0.79-1.64)$ & $1.20(0.81-1.92)$ & $0.95(0.72-1.10)$ & $<0.001$ \\
\hline$A L T, U / L$ & $37.0(24.0-63.7)$ & $36.0(22.0-62.0)$ & $42.5(26.7-68.5)$ & 0.035 \\
\hline Ferritin $n g / m L$ & $622(338-1130)$ & $648(368-1217)$ & 479 (249-1009) & 0.011 \\
\hline$H S$-troponin $I, n g / L$ & $29.0(11.0-126.2)$ & $49.5(17.0-226.0)$ & $27.1(11.0-174.0)$ & $<0.001$ \\
\hline$\Delta-\delta \imath \mu \epsilon \rho, \mu \gamma / \mu \Lambda$ & $1.60(1.00-3.87)$ & $2.00(1.20-5.80)$ & $1.05(0.50-1.85)$ & $<0.001$ \\
\hline $\begin{array}{l}B N P \text { (plasma), } \\
p g / m L^{*}\end{array}$ & $118(46-324)$ & $139(61-415)$ & $72(21-172)$ & 0.001 \\
\hline$C R P, m g / L$ & $155.0(84.7-228.2)$ & $169.0(91.3-243.5)$ & $124.0(74.0-191.3)$ & 0.009 \\
\hline $\begin{array}{l}\text { Procalcitonin, } \\
n g / m L\end{array}$ & $0.33(0.13-1.14)$ & $0.46(0.19-1.88)$ & $0.14(0.07-0.28)$ & $<0.001$ \\
\hline$\Omega B^{\mathrm{c}}, \xi 10^{3} / \mu \Lambda$ & $11.1(7.9-15.1)$ & $12.2(8.3-16.8)$ & $9.4(7.3-11.9)$ & 0.001 \\
\hline $\begin{array}{l}N \epsilon \nu \tau \rho \circ \pi \eta \lambda, \xi \\
10^{3} / \mu \Lambda\end{array}$ & $9.6(6.8-13.9)$ & $10.4(7.0-14.8)$ & $8.3(5.9-10.8)$ & 0.002 \\
\hline Hemoglobin, $g / d L$ & $12.5(10.8-13.8)$ & $12.2(10.3-13.6)$ & $12.9(11.7-14.0)$ & 0.007 \\
\hline $\begin{array}{l}\text { Arterial blood } \\
\text { gas analysis }\end{array}$ & $\begin{array}{l}\text { Arterial blood } \\
\text { gas analysis }\end{array}$ & $\begin{array}{l}\text { Arterial blood } \\
\text { gas analysis }\end{array}$ & $\begin{array}{l}\text { Arterial blood } \\
\text { gas analysis }\end{array}$ & $\begin{array}{l}\text { Arterial blood } \\
\text { gas analysis }\end{array}$ \\
\hline$p H$ & $7.41(7.32-7.47)$ & $7.38(7.29-7.46)$ & $7.44(7.39-7.48)$ & 0.001 \\
\hline $\mathrm{HCO}_{3}, \mathrm{mmol} / \mathrm{L}$ & $22.2(19.6-25.0)$ & $22.0(18.0-24.6)$ & $24.2(21.7-26.0)$ & $<0.001$ \\
\hline Lactate, $\mathrm{mmol} / \mathrm{L}$ & $2.00(1.40-3.00)$ & $2.10(1.47-3.20)$ & $1.80(1.20-2.40)$ & 0.002 \\
\hline $\begin{array}{l}\text { Events/therapies } \\
\text { during ICU } \\
\text { stay }\end{array}$ & $\begin{array}{l}\text { Events/therapies } \\
\text { during ICU } \\
\text { stay }\end{array}$ & $\begin{array}{l}\text { Events/therapies } \\
\text { during ICU } \\
\text { stay }\end{array}$ & $\begin{array}{l}\text { Events/therapies } \\
\text { during ICU } \\
\text { stay }\end{array}$ & $\begin{array}{l}\text { Events/therapies } \\
\text { during ICU } \\
\text { stay }\end{array}$ \\
\hline$I M V$ & $198(79.8)$ & $173(99.4)$ & $25(33.8)$ & $<0.001$ \\
\hline
\end{tabular}




\begin{tabular}{lllll}
\hline Characteristics & All Cases & Dead group & Alive group & P value \\
\hline $\begin{array}{l}\text { Vasopressor } \\
\text { requirement }\end{array}$ & $166(66.9)$ & $151(86.8)$ & $15(20.3)$ & $<0.001$ \\
$\begin{array}{l}\text { VAP } \\
\begin{array}{l}\text { Secondary bacterial } \\
\text { infections }\end{array}\end{array}$ & $95(38.3)$ & $87(50.0)$ & $8(10.8)$ & $<0.001$ \\
$\begin{array}{l}\text { Acute kidney injury } \\
\text { Renal replacement }\end{array}$ & $135(54.4)$ & $117(67.2)$ & $20(27.0)$ & $<0.001$ \\
$\begin{array}{l}\text { therapy } \\
\text { Cardiac injury }\end{array}$ & $159(64.1)$ & $123(70.7)$ & $12(16.2)$ & $<0.001$ \\
NOAF & $37(14.9)$ & $131(75.3)$ & $4(5.4)$ & $<0.001$ \\
\hline
\end{tabular}

Note: All values are expressed as numbers (percentages) or median (interquartile range).

Abbreviations: APACHE II, Acute Physiology and Chronic Health Evaluation II; ALT, alanine transaminase; BUN, blood urea nitrogen; CCI, Charlson Comorbidity Index; COPD, chronic obstructive pulmonary disease; CRP, C-reactive protein; HS Troponin I, high-sensitive troponin I; IMV, invasive mechanical ventilation; SOFA Score, The Sequential Organ Failure Assessment Score; VAP, ventilator associated pneumonia; WBC, white blood cell count.

*. $\mathrm{N}=215$

Table 3. Logistic regression analysis for risk factors of hospital mortality

\begin{tabular}{lll}
\hline & OR $(95 \%$ CI $)$ & P value \\
\hline Vasopressor requirement & $12.20(5.12-29.05)$ & $<\mathbf{0 . 0 0 1}$ \\
AKI & $4.53(1.87-10.92)$ & $\mathbf{0 . 0 0 1}$ \\
Charlson comorbidity index & $1.36(1.10-1.66)$ & $\mathbf{0 . 0 0 3}$ \\
APACHE II & $0.99(0.92-1.06)$ & 0.822 \\
SOFA $^{*}$ & $1.22(0.95-1.58)$ & 0.108 \\
New-onset atrial fibrillation & $1.42(0.40-5.09)$ & 0.582 \\
\hline
\end{tabular}

Abbreviations: AKI, acute kidney injury; APACHE II, Acute Physiology and Chronic Health Evaluation II; CI, confidence interval; OR, odds ratio; SOFA, The Sequential Organ Failure Assessment Score.

* Calculated on the day of ICU admission. 